Marquette University

e-Publications@Marquette

College of Nursing Faculty Research and

Publications

Nursing, College of

$11-1-2008$

\title{
The Influence of Religiosity, Gender, and Language Preference Acculturation on Sexual Activity Among Latino/a Adolescents
}

Lisa Edwards

Marquette University, lisa.edwards@marquette.edu

Richard Fehring

Marquette University, richard.fehring@marquette.edu

Keyona M. Jarrett

Marquette University

Kristin Haglund

Marquette University, kristin.haglund@marquette.edu

Accepted version. Hispanic Journal of Behavioral Sciences, Vol. 30, No. 4 (November 2008): 447-462.

DOI. (C) 2008 SAGE Publications. Used with permission. 


\title{
The Influence of Religiosity, Gender, and Language Preference Acculturation on Sexual Activity Among Latino/a Adolescents
}

\author{
By Lisa M. Edwards, Richard J. Fehring, Keyona M. Jarrett, Kristin A. Haglund
}

The purpose of this study was to determine the main and interactive effects of religiosity, gender, and language preference acculturation on sexual activity among 570 Latino/a adolescents from the 2002 National Survey of Family Growth. Results indicated that adolescents who viewed religion as very important, had frequent church attendance, and had more traditional attitudes on sexuality were less likely ever to have sex compared with adolescents who were less religious. Those with frequent church attendance and high traditional attitudes had fewer lifetime and recent sex partners. Unassimilated religious youth were less likely ever to have sex, had fewer lifetime and recent sexual partners, and a later age of sexual debut. Females were less likely to have had sex, had fewer recent and lifetime partners, and had a later age of coital debut than males. Religiosity had a healthy dampening of sexual activity among Latino/a adolescents and, in particular, among those who were less assimilated.

Early sexual activity among adolescents bears variable consequences in physical, psychological, and emotional domains. Consequences such as sexually transmitted infections and teenage pregnancy have been identified as concerns for youths (Forste \& Heaton, 1988; Holder et al., 2000), and the effects of childbearing on girls may include poverty, mental illness, under-performance in school, sexual violence and abuse, family dysfunction, and poor self-esteem (Contreras, Narang, Ikhlas, \& Teichman, 2002). Even with these potential consequences, adolescents continue to engage in sexual behaviors at early ages. National representative data from the Youth Risk Behavior Survey revealed that $63 \%$ of youths have had sex by 12 th grade (Eaton et al., 2006).

Latino/a adolescents report high rates of sexual activity. Among high school students, $51 \%$ of Latino/a youth reported engaging in sexual activity, compared with $43 \%$ of Caucasian youth (Eaton et al., 2006). By the 12 th grade, $75 \%$ of Latino males and $64 \%$ of Latina females reported having had sex. Also, among these high school students, $22 \%$ of Latinos and $10 \%$ of Latinas reported having had four or more sexual partners (Centers for Disease Control and Prevention, 2007).

The high rates of sexual behavior and related consequences have prompted researchers to explore factors that may influence sexual behavior among Latino/a adolescents, such as religiosity 
(DuRant, Pendergrast, \& Seymore, 1990; Forste \& Heaton, 1988; Holder et al., 2000; Liebowitz, Castellano, \& Cuellar, 1999), gender (Liebowitz et al., 1999; Upchurch, Aneshensel, Mudgal, \& McNeely, 2001; Vélez-Pastrana, Gonzalez-Rodriguez, \& Borges-Hernandez, 2005), and acculturation (Afable-Munsuz \& Brindis, 2006; Driscoll, Biggs, Brindis, \& Yankah, 2001; Upchurch et al., 2001). However, researchers have yet to examine the relationships among all of these factors and the sexual behaviors of Latino/a adolescents in a nationally representative sample.

\section{Religiosity and Sexual Behavior}

Religion has been broadly defined as a set of institutionalized beliefs in a higher power and includes statutes or regulations for how to guide one's life (Holder et al., 2000). Previous research has identified relationships between religiosity and sexual behaviors. Adolescents who attended church more frequently had less sexual experience (Forste \& Heaton, 1988; Sinha, Cnaan, \& Gelles, 2007; Thornton \& Camburn, 1989) and had fewer sexual partners (Lefkowitz, Gillen, Shearer, \& Boone, 2004) than those who had less frequent church attendance. Youths who reported high levels of religious importance, strong religious influence in their daily lives, and adherence to their religion's teachings were less likely to initiate sexual activity than their peers (Holder et al., 2000; Lefkowitz et al., 2004; Thornton \& Camburn, 1989). For males and females, each unit increase in religiosity (composite of importance of religion and attendance at religious services and youth activities) reduced the likelihood of sexual initiation by $12 \%$ to $16 \%$ (Rostosky, Regnerus, \& Wright, 2003). Most research supports that adolescents who are more religious tend to delay sexual activity (Rostosky, Wilcox, Wright, \& Randall, 2004), with the exception of a handful of studies that report no relationship (Benson \& Torpy, 1995; Sheeran, Abrams, Abraham, \& Spears, 1993) or a negative relationship (Sinha et al., 2007) between religiosity and sexual activity.

Researchers have reported that religious teens tend to endorse traditional attitudes on sexuality (Koenig, 2004; Lefkowitz et al., 2004; Sheeran et al., 1993; Thornton \& Camburn, 1989). However, the relationship between sexual attitudes and sexual behaviors is not clear. It has been reported that traditional sexual values were related to less sexual activity (Thornton \& Camburn, 1989) or unrelated to sexual behaviors (Sheeran et al., 1993). In addition to these contradictions in the literature, few studies have focused specifically on Latino/a youth. More research examining the relationship between religiosity and sexual activity among Latino/a adolescents is therefore needed.

\section{Gender and Acculturation Influences on Sexual Behavior}

Edwards, Fehring, Jarrett, Haglund 2 
There is some evidence that Latino adolescent males and females differ in their sexual behavior. Several studies have found that Latino adolescents tend to be more sexually active than their Latina counterparts (Liebowitz et al., 1999; Upchurch et al., 2001; Vélez-Pastrana et al., 2005). The tendency for males to be more sexually active than females may be a manifestation of Latino cultural values, such as machismo and marianismo, which prescribe traditional gender roles (Schuster, 2003). Machismo is a concept that describes the male role as dominant, independent, and protective of the family, whereas marianismo refers to the female role as a caregiver, a virgin, and obedient to men (Gloria, Ruiz, \& Castillo, 2004; Upchurch et al., 2001). Men are allowed sexual freedom, while women are expected to maintain their virginity (Schuster, 2003).

The influence of machismo and marianismo in the lives of Latino adolescents may depend on their level of acculturation. Acculturation has been defined as the process by which one is influenced by the host culture and one's own culture of membership (Berry, 2003). Measures of acculturation are both attitudinal and behavioral. Common indicators include cultural identification, pride, and acceptance; language preference and proficiency; traditions and customs; styles of communication; and social affiliations (Zane \& Mak, 2003). Research suggests that as individuals become more assimilated to White, majority culture, for example, their cultural values may change to reflect those of the dominant culture. Regarding gender roles, some Latino/a adolescents may adhere strongly to these values, whereas others may have assimilated to a degree and abandoned their cultural values of machismo and marianismo for more egalitarian gender roles (Marín \& Gamba, 2003).

Researchers have suggested that some traditional cultural values may serve as protective factors against risky sexual behavior (Schuster, 2003). For example, as Latina adolescent females become more assimilated, they may no longer prescribe to marianismo and thus may be more likely to engage in risky sexual behaviors. Multiple studies have indicated that less assimilated Latino male and female adolescents are significantly less likely to have had sex than their more assimilated peers (Afable-Munsuz \& Brindis, 2006; Jimenez, Potts, \& Jimenez, 2002; Upchurch et al., 2001). When asked about their reasons for abstaining, less assimilated Latinas more frequently reported waiting until marriage than highly assimilated Latinas (Jimenez et al., 2002).

\section{The Current Study}

This study was designed to investigate the influence of religiosity, gender, and acculturation on the sexual activity of Latino adolescents in order to provide a more comprehensive understanding of their sexual behavior. There were several ways in which the current study extended existing research. 
Many previous studies used one-item measures of sexual activity, such as ever had sex (Durant et al., 1990; Holder et al., 2000; Rostosky et al., 2003), age at sexual debut (Forste \& Heaton, 1988; Manlove, Terry-Humen, Ikramullah, \& Moore, 2006), or frequency of sexual activity (Liebowitz et al., 1999). The current study sought to measure teen sexual activity more comprehensively by including four indicators of sexual activity.

In addition, many previous studies are limited in their measurement of religiosity (Durant et al., 1990; Lefkowitz et al., 2004; Manlove et al., 2006; Vélez-Pastrana et al., 2005). The influence of religiosity on attitudes about sexuality and how those attitudes influence behavior were not often considered. Thus, the current study extended existing research by including traditional attitudes on sexuality as a measure of religiosity. Finally, this study further developed the current literature by exploring the influences of religion, gender, and acculturation on the sexual activity of Latino males and females into their early 20 s utilizing a nationally representative sample.

This research was informed by several theoretical perspectives, including reference group theory (Lefkowitz et al., 2004; Thornton \& Camburn, 1989) and the protection-risk conceptual framework (Jessor et al., 2003). Reference group theory, which posits that one adheres to the doctrine of one's religion when determining attitudes and behaviors, would suggest that Latino youth will reference their religion's principles concerning delaying or abstaining from sexual behavior. A protection-risk conceptual framework suggests that religiosity can be considered a protective factor against early sexual activity, because it provides models of positive behavior, has sanctions against problem behavior, and often fosters a supportive environment (Jessor et al., 2003).

Based on theory and existing empirical research the following hypotheses were formulated: (a) there will be less sexual activity among Latino/a adolescents who are more religious and less assimilated when compared with those who are less religious and more assimilated, (b) Latino male adolescents will score higher on measures of sexual activity than Latinas, and (c) an interaction between gender and acculturation will exist such that unassimilated Latina adolescents will score the lowest on measures of sexual activity, and assimilated Latino male adolescents will score the highest on measures of sexual activity for all groups.

\section{Method}

\section{Participants}

Participant data were from Cycle 6 of the National Survey of Family Growth (National Center for Health Statistics [NCHS], 2007), a periodic government survey about family, gender, and sexuality. Cycle Edwards, Fehring, Jarrett, Haglund 4 
6 was conducted in 2002 by the NCHS. Male and female participants were selected from an area probability sample to yield a nationally representative sample, and there was about a $79 \%$ return rate. Data were gathered during confidential, in-person interviews, each lasting 60 to 90 minutes.

There were 7,365 female and 4,928 male participants in Cycle 6. Of these, 1,675 females and 1,494 males were between the ages of 15 and 21, of which 322 females (19.2\%) and 302 males (20.2\%) identified themselves as Hispanic. Fifty-four married participants were removed from the data set as it was unknown whether sexual debut occurred prior to their marriage. The final data set utilized in this study included 570 Latino/a adolescents ( 287 males and 283 females). The mean age of the total ( $N=$ 570 ) respondents was 17.91 years $(S D=1.98)$, with an age range of $15-22$ years. ${ }^{1}$ The mean age of the 283 female respondents was 17.88 years $(S D=1.97)$, with an age range of $15-22$ years; the mean age for the male respondents was 17.93 years $(S D=2.00)$, with an age range of $15-21$ years.

Of the 3,456 variables, the authors analyzed several demographic variables (i.e., age, religion, and Hispanic origin) as well as the following dependent variables: (a) ever being sexually active, (b) number of sexual partners in a lifetime, (c) the number of sexual partners in the past 12 months, and (d) age of sexual debut.

The independent variable of religiosity was measured by importance of religion, frequency of attendance at religious services, and by a combination of four variables that reflected traditional attitudes on human sexuality. Importance of religion in the respondent's daily life was originally recorded as: 1 (Very important), 2 (Somewhat important), and 3 (Not important). For analysis purposes these responses were dichotomized into two categories: 1 (Very important) and 2 (Not important), which included somewhat and not important. Original responses to frequency in religious attendance included: 1 (More than once a week), 2 (Once a week), 3 (1-3 times per month), 4 (Less than once a month), and 5 (Never). For analysis purposes, the responses were collapsed into two categories: (a) Frequent Church Attendance, which included more than once a week and once a week; and (b) Not Frequent Church Attendance (i.e., 1-3 times per month, less than once a month, and never). The independent variable of Traditional Attitudes on Sexuality (TAS) was measured by combining four items and summing a total score. The items were (a) sexual acts between two consenting adults is $\mathrm{OK},(\mathrm{b})$ it is OK for unmarried 16 year olds to have sex if there is a strong affection, (c) it is OK for unmarried 18-year-olds to have sex if there is a strong affection, and (d) it is OK for an unmarried female to have a child. Response options included strongly agree, agree, not sure, disagree, or strongly disagree. A high total score indicated that the respondent possessed traditional attitudes on sexuality and a low score indicated permissive attitudes.

Edwards, Fehring, Jarrett, Haglund 5 
The variable of language preference acculturation was determined by the language of communication at the time of the interviews. Participants who preferred to be interviewed in English were considered assimilated into U.S. society and those who preferred Spanish were considered unassimilated. Although language preference at time of interview is not a comprehensive or direct indicator of acculturation, language spoken in the home has been used to assess acculturation (Guilamo-Ramos, Jaccard, Pena, \& Goldberg, 2005; Nguyen, Messe, \& Stollak, 1999).

\section{Statistical Analyses}

Means, standard deviations, frequencies, and percentages were used to describe the participants. The sample was grouped according to gender, language preference acculturation, and religiosity (religion is very important vs. religion is less important, frequent church attendance vs. less frequent church attendance, and holding traditional attitudes on sexual activity vs. holding permissive attitudes on sexuality). Chi-square and likelihood odds ratios (ORs) were used to determine the likelihood of ever having had sexual intercourse. Student $t$ tests were used to determine the differences of sexual activity with the continuous dependent variables of number of partners in a lifetime and the number of partners in the past 12 months. To determine the influence of religiosity on the age of sexual debut, survival analysis was used (Kaplan \& Meier, 1958). The censored event was sexual debut or not, and the time was the current age of the participant (if still a virgin) or the age of debut if the participant had initiated sexual activity. Interaction effects of gender and religiosity and language preference acculturation and religiosity on sexual activity were determined by a $2 \times 2$ univariate analysis of variance. The minimal level of statistical significance was set at $p<.05$.

\section{Results}

The frequency and percentage of the demographic variables by gender can be found in Table 1. The majority (57.1\%) reported being of Mexican or Mexican American background, and 39.3\% were of another Hispanic group. Most of the 570 participants listed Roman Catholic as their current religion (62.8\%), with Protestant as the second most frequent choice (21.6\%) and "No Religion" as the third most frequent choice (12.5\%). Table 1 shows the breakdown for frequency of age, religion, Hispanic-origin group, primary language, and education, as all variables were reported in the National Survey of Family Growth data set (NCHS, 2007), by gender.

\section{Religiosity and Sexual Activity}

Importance of religion. Adolescents who viewed religion as very important were $23.4 \%$ less likely ever to

Edwards, Fehring, Jarrett, Haglund 6 
have had sex compared with adolescents who viewed religion as not important (OR $=0.766$; $95 \%$ confidence interval $[\mathrm{Cl}]=0.621-0.945)$. Those who viewed religion as very important had significantly fewer lifetime sexual partners (mean $=1.6 ; S D=2.16$ ) than those who viewed religion as not important (mean $=2.3 ; S D=3.02$ ), with $t=3.07, p<.002$. There was no significant difference in the number of sexual partners in the past 12 months. The cumulative survival of virgins at 21 years of age was $19.8 \%$ for those who viewed religion as very important compared with $4.6 \%$ for those who viewed religion as not important (see Table 2 for estimated ages of sexual debut).

Church attendance. Adolescents who attended church services at least once a week were $39.5 \%$ less likely ever to have had sex compared with adolescents who attended church less frequently or not at all $(\mathrm{OR}=0.605 ; 95 \% \mathrm{Cl}=0.475-0.772)$. Adolescents who had high church attendance had significantly fewer lifetime sexual partners (mean $=1.4 ; S D=2.2$ vs. mean $=2.4 ; S D=2.4 ; t=3.97, p<.001$ ) and fewer sexual partners in the past 12 months (mean $=0.6 ; S D=1.1$ vs. mean $=1.1 ; S D=1.4 ; t=3.737, p$ $<.001)$ compared with those with low attendance. The cumulative survival of virgins at age 21 for the high attendance group was $24 \%$ compared with $5.6 \%$ for the low attendance group (see Table 2).

Traditional attitudes on sexuality (TAS). Participants who held traditional attitudes on sexuality were $55 \%$ less likely to ever have had sex compared with adolescents who had less traditional attitudes $(O R=0.450 ; 95 \% \mathrm{Cl}=0.349-0.581)$. Those who held TAS had significantly fewer lifetime sexual partners (mean $=1.4 ; S D=2.2$ vs. mean $=2.4 ; S D=2.9 ; t=4.11, p<.001)$ and fewer sexual partners in the past 12 months (mean $=0.5 ; S D=0.9$ vs. mean 1.0; $S D=0.9 ; t=4.49, p<.001$ ). The cumulative survival of virgins at age 21 for the high TAS group was $45 \%$ compared with $7.2 \%$ for the low TAS group (see Table 2).

\section{Gender, Religiosity, and Sexual Activity}

Latinas were $19.2 \%$ less likely ever to have had sex than Latinos $(\mathrm{OR}=0.808 ; 95 \% \mathrm{Cl}=$ $0.686-0.952$ ). Females also had significantly fewer lifetime sexual partners (mean $=1.6 ; S D=2.7$ vs. mean $=2.5 ; S D=2.7 ; t=3.978, p<.001)$ and fewer partners in the past 12 months than their male peers ( mean $=0.7 ; S D=1$ vs. mean $=1 ; S D=1.5 ; t=2.990, p<.003)$. Mean age in years at coital debut was 13 for males $(N=124)$ and 15 for females $(N=149 ; t=7.75, p=.00)$. In addition, the cumulative survival of virgins at the age of 21 was $28.9 \%$ for females and $6.1 \%$ for males (see Table 2).

There was no significant interaction effect between gender and sexual activity with regard to importance of religion and TAS. There was a significant interaction between gender, sexual activity, and church attendance. Females were more likely to attend church at least once a week and have fewer sexual partners in the past 12 months compared with the male adolescents. 


\section{Language Preference Acculturation, Religiosity, and Sexual Activity}

There was no difference in the likelihood of ever having had sex between the English language acculturation (assimilated) versus Spanish language acculturation (nonassimilated) adolescents. However, the nonassimilated adolescents had significantly fewer lifetime sexual partners (mean = 1.3; $S D=1.7$ vs. mean $=2.2 ; S D=2.9 ; t=2.812, p<.005)$ and fewer sexual partners in the past 12 months $($ mean $=0.6 ; S D=0.7$ vs. mean $=0.9 ; S D=1.4 ; t=2.554, p<.011)$ compared with the assimilated adolescents. The cumulative rate of remaining a virgin at age 21 was $12 \%$ for the nonassimilated adolescents and $8 \%$ for the assimilated adolescents (see Table 2).

There was a significant interaction effect of language preference acculturation and importance of religion, church attendance, and TAS on the variables of number of sexual partners in a lifetime, number of sexual partners in the past 12 months, and age of sexual debut (see Table 3). Unassimilated adolescents who held religion as very important, attended church at least once a week, and had traditional attitudes on sexuality were less likely to ever have had sex, more likely to have had fewer sexual partners in the past 12 months and in their lifetime, and to have had a later age at coital debut.

\section{Discussion}

The results of this study about religiosity and sexual activity in Latino/a youth support a growing body of research that indicates that increased religiosity decreases sexual risk for youths (Durant et al., 1990; Forste \& Heaton, 1988; Holder et al., 2000; Liebowitz et al., 1999). Religiosity had a robust influence on helping youths to avoid sexual activity, thus providing support for the study's first hypothesis. Specifically, the three indicators of religiosity, viewing religion as important, attending church services often, and holding traditional sexual attitudes, were independently related to increased sexual abstinence through age 21 and decreased lifetime partners. Frequent church attendance and holding TAS were also related to decreased partners in the past 12 months. These results may indicate that religious youths are internalizing religious doctrine and translating it into attitudes and behaviors as theorized by reference group theory (Lefkowitz et al., 2004; Thornton \& Camburn, 1989). Though not explicitly measured in this study, it is possible that religious doctrine may be shared and reinforced within a church-based social network of adolescent peers. In one study, youths who perceived social support from their spiritual friends were more likely to be virgins (Holder et al., 2000). Similarly, Bazargan and West (2006) found that those Hispanic and African American youths who experienced less peer pressure to engage in sexual activity and perceived a lower level of peer norms for engaging in risky behaviors were more likely to remain sexually inactive.

Edwards, Fehring, Jarrett, Haglund 8 
In the current study, Latina adolescents reported increased rates of abstinence and higher survival rates through age 21 and fewer partners in the past 12 months and in their lifetimes compared with their male counterparts. This provided support for the study's second hypothesis about gender, and was similar to previous research in which Latino males reported increased rates of sexual initiation and more partners than females (Driscoll et al., 2001; Eaton et al., 2006). In the present study, both males and females reported early ages at coitarche, 13 and 15 years, respectively, although males were significantly younger. National data from the Youth Risk Behavior Survey revealed similar gender differences, in that $11 \%$ of Latino males and $4 \%$ of Latina females reported coitarche before age 13 , and by ninth grade, $51 \%$ of Latino males and $31 \%$ of Latina girls reported having had sex (Centers for Disease Control and Prevention, 2007).

Results in this study provided support for the third hypothesis. Adolescents who indicated Spanish as their preferred language had significantly fewer lifetime sexual partners, fewer sexual partners in the past 12 months, and higher rates of virginity at age 21 compared with those adolescents who preferred to be interviewed in English. These results indicate that less assimilation may also be protective for youth in terms of avoiding sexual risks. Results of previous studies have found that highly assimilated Latino adolescents are more likely to have had sex than less assimilated Latino adolescents (Afable-Munsuz \& Brindis, 2006; Jimenez et al., 2002; Upchurch et al., 2001).

Taken together, these findings suggest that providing support for youths to maintain their ethnic cultural heritage may help them to more readily abstain from intercourse and have fewer partners. Researchers have begun to test culturally tailored HIV prevention interventions and have reported significant outcomes including decreased sexual activity, decreased number of partners, increased abstinence, and increased use of condoms (Crepaz et al., 2007; Villarruel, Jemmott, \& Jemmott, 2006). These efforts should continue to be explored.

It is important to note limitations in the current study, as well as areas for future research. First, although language preference has been used frequently as a marker of acculturation (Guilamo-Ramos et al., 2005; Nguyen et al., 1999), acculturation is a more complex, multidimensional construct that goes beyond preferred language (Zane \& Mak, 2003). It is possible, therefore, that our study did not capture the true level of acculturation of participants, and it is important for future studies to consider using a more comprehensive measure.

In addition, our indicators of religiosity may not have accounted for the complexity of religious faith, attendance, and beliefs. Although it is noteworthy that we included items about importance, attendance, and traditional beliefs, respondents' views on religion or the nature of their personal beliefs Edwards, Fehring, Jarrett, Haglund 9 
were not assessed. It would be helpful for future research to consider including a validated measure of religious faith rather than just individual items.

The results of this study contribute to a growing body of knowledge about protective influences in the lives of Latino youth with respect to delaying sexual activity. The findings extend the literature by investigating the influence of religion, gender, and acculturation on the sexual activity of Latino adolescents into their early 20 s using a nationally representative sample. Future studies that identify trends in adolescent attitudes and behaviors over time will help to further extend the field, as will continued research about gender and cultural influences that help prevent or delay early and risky sexual behaviors among Latino youth.

\section{Note}

1. Although our age limit was 21 years, one of the female participants provided two different ages (21 and 22) during the interview.

\section{References}

Afable-Munsuz, A., \& Brindis, C. D. (2006). Acculturation and the sexual and reproductive health of Latino youth in the United States: A literature review. Perspectives on Sexual and Reproductive Health, 38, 208-219.

Bazargan, M., \& West, K. (2006). Correlates of the intention to remain sexually inactive among underserved Hispanic and African American high school students. Journal of School Health, 76, 25-32.

Benson, M., \& Torpy, E. (1995). Sexual behavior in junior high school students. Obstetrics \& Gynecology, $85,279-284$.

Berry, J. W. (2003). Conceptual approaches to acculturation. In K. M. Chun, P. B. Organista, \& G. Marín (Eds.), Acculturation: Advances in theory, measurement, and applied research (pp. 17-37). Washington, DC: American Psychological Association.

Centers for Disease Control and Prevention. (2007). YRBSS Youth online: Comprehensive results. Retrieved October 5, 2007, from http://apps.nccd.cdc.gov/yrbss/

Contreras, J. M., Narang, D., Ikhlas, M., \& Teichman, J. (2002). A conceptual model of the determinants of parenting among Latina adolescent mothers. In J. Contreras, K. Kerns, \& A. M. Neal-Barnett (Eds.), Latino children and families in the United States: Current research and future directions (pp. 155-177). Westport, CT: Praeger.

Edwards, Fehring, Jarrett, Haglund 10 
Crepaz, N., Horn, A., Rama, S., Griffin, T., Deluca, J., Mullins, M., et al. (2007). The efficacy of behavioral interventions in reducing HIV risk sex behaviors and incident sexually transmitted disease in Black and Hispanic sexually transmitted disease clinic patients in the United States: A meta-analytic review. Sexually Transmitted Diseases, 34, 319-332.

Driscoll, A. K., Biggs, M. A., Brindis, C. D., \& Yankah, E. (2001). Adolescent Latino reproductive health: A review of the literature. Hispanic Journal of Behavioral Sciences, 23, 255-326.

DuRant, R. H., Pendergrast, R., \& Seymore, C. (1990). Sexual behavior among Hispanic female adolescents in the United States. Pediatrics, 85, 1051-1058.

Eaton, D., Kann, L., Kinchen, S., Ross, J., Hawkins, J., Harris, W., et al. (2006).Youth risk behavior surveillance: United States, 2005. Morbidity and Mortality Weekly Report, 55(SS-5), 1-108.

Forste, R. T., \& Heaton, T. B. (1988). Initiation of sexual activity among female adolescents. Youth \& Society, 19, 250-268.

Gloria, A. M., Ruiz, E. L., \& Castillo, E. M. (2004). Counseling and psychotherapy with Latino and Latina clients. In T. B. Smith (Ed.), Practicing multiculturalism: Affirming diversity in counseling and psychology (pp. 167-189). Boston: Pearson Education.

Guilamo-Ramos, V., Jaccard, J., Pena, J., \& Goldberg, V. (2005). Acculturation-related variables, sexual initiation and subsequent sexual behavior among Puerto Rican, Mexican and Cuban youth. Health Psychology, 24, 88-95.

Holder, D. W., Durant, R. H., Harris, T. L., Daniel, J. H., Obeidallah, D., \& Goodman, E. (2000). The association between adolescent spirituality and voluntary sexual activity. Journal of Adolescent Health, 26, 295-302.

Jessor, R., Turbin, M. S., Costa, F. M., Dong, Q., Zhang, H., \& Wang, C. (2003). Adolescent problem behavior in China and the United States: A cross-national study of psychosocial protective factors. Journal of Research on Adolescence, 13, 329-360.

Jimenez, J., Potts, M. K., \& Jimenez, D. R. (2002). Reproductive attitudes and behavior among Latina adolescents. Social Work with Multicultural Youth, 11, 221-249.

Kaplan, E. L., \& Meier, P. (1958). Nonparametric estimation from incomplete observations. Journal of the American Statistical Association, 53, 457-485.

Koenig, H. G. (2004). Spirituality, wellness, and quality of life. Sexuality, Reproduction \& Menopause, 2, 76-82.

Lefkowitz, E. S., Gillen, M. M., Shearer, C. L., \& Boone, T. L. (2004). Religiosity, sexual behavior, and sexual attitudes during emerging adulthood. Journal of Sex Research, 41, 150-159.

Edwards, Fehring, Jarrett, Haglund 11 
Liebowitz, S. W., Castellano, D. C., \& Cuellar, I. (1999). Factors that predict sexual behavior among young Mexican American adolescents: An exploratory study. Hispanic Journal of Behavioral Sciences, $21,470-479$.

Manlove, J. S., Terry-Humen, E., Ikramullah, E. N., \& Moore, K. A. (2006). The role of parent religiosity in teen's transitions to sex and contraception. Journal of Adolescent Health, 39, 578-587.

Marín, G., \& Gamba R. J. (2003). Acculturation and changes in cultural values. In K. M. Chun,

P. B. Organista, \& G. Marín (Eds.), Acculturation: Advances in theory, measurement, and applied research (pp. 83-93). Washington, DC: American Psychological Association. National Center for Health Statistics (NCHS). (2007). National Survey of Family Growth. Retrieved October 5 , 2007, from http://www.cdc.gov/nchs/nsfg.htm Nguyen, H. H., Messe, L. A., \& Stollak, G. E. (1999). Toward a more complex understanding of acculturation and adjustment. Journal of Cross-Cultural Psychology, 30, 5-31. Rostosky, S. S., Regnerus, M. D., \& Wright, M. L. C. (2003). Coital debut: The role of religiosity and sex attitudes in the add health survey. Journal of Sex Research, 40, 358-367. Rostosky, S., Wilcox, B., Wright M., \& Randall, B. (2004). The impact of religiosity on adolescent sexual behavior: A review of the evidence. Journal of Adolescent Research, 19, 677-697.

Schuster, C. (2003, September). Issues at a glance: Latina adolescent health. Washington, DC: Advocates for Youth. Retrieved June 10, 2007, from http://www.advocatesforyouth. org/publications/iag/latina.htm.

Sheeran, P., Abrams, D., Abraham, C., \& Spears, R. (1993). Religiosity and adolescents' premarital sexual attitudes and behavior: An empirical study of conceptual issues. European Journal of Social Psychology, 23, 39-52.

Sinha, J. W., Cnaan, R. A., \& Gelles, R. J. (2007). Adolescent risk behaviors and religion: Findings from a national study. Journal of Adolescence, 30, 231-249.

Thornton A., \& Camburn D. (1989). Religious participation and adolescent sexual behavior and attitudes. Journal of Marriage and Family, 51, 641-653.

Upchurch, D. M., Aneshensel, C. S., Mudgal, J., \& McNeely, C. S. (2001). Sociocultural contexts of time to first sex among Hispanic adolescents. Journal of Marriage and Family, 63, 1158-1169.

Vélez-Pastrana, M. C., Gonzalez-Rodriguez, R. A., \& Borges-Hernandez, A. (2005). Family functioning and early onset of sexual intercourse in Latino adolescents. Adolescence, 40, 777-791.

Villarruel, A. M., Jemmott, J. B., III, \& Jemmott, L. S. (2006). A randomized controlled trial testing an HIV prevention intervention for Latino youth. Archives of Pediatrics \& Adolescent Medicine, 160,

Edwards, Fehring, Jarrett, Haglund 12 
772-777.

Zane, N., \& Mak, W. (2003). Major approaches to the measurement of acculturation among ethnic minority populations: A content analysis and an alternative empirical strategy. In

K. M. Chun, P. B. Organista, \& G. Marín (Eds.), Acculturation: Advances in theory, measurement, and applied research (pp. 39-60). Washington, DC: American Psychological Association.

Lisa M. Edwards, PhD, is an assistant professor in the Department of Counseling and Educational Psychology at Marquette University. She received her doctorate in counseling psychology from the University of Kansas and was previously a research associate at the University of Notre Dame. Her current research focuses on positive functioning and wellbeing among racial/ethnic minorities in the United States.

Richard J. Fehring, PhD, RN, is a professor and Director of the Marquette University College of Nursing Office of Research and Scholarship. He received his master's degree and doctorate in nursing from Catholic University of America and baccalaureate degrees in biology and nursing from Marquette University. He has published more than 100 articles and book chapters and has edited two books. His research interests include effectiveness of fertility awareness methods of family planning, marital responses to family planning, and variability in the parameters of the menstrual cycle.

Keyona M. Jarrett, MA, is a doctoral student in the Counseling and Educational Psychology Program at Marquette University. She received her bachelor's of arts degree in both Psychology and Hispanic Studies from Illinois Wesleyan University. Her research interests include racial identity, stress, and well-being among racial and ethnic minority individuals.

Kristin A. Haglund, PhD, RN, is an assistant professor in the College of Nursing at Marquette University. She received her doctorate in nursing from University of Wisconsin, Milwaukee. She has worked as a nurse practitioner specializing in primary care of adolescents for 12 years. Her research has focused on adolescent sexuality and sexual risk reduction.

Edwards, Fehring, Jarrett, Haglund 13 


\section{Appendix}

\section{Table 1}

Demographic Variables of Male and Female Adolescent Latino/a Respondents

\begin{tabular}{|c|c|c|c|c|}
\hline \multirow[b]{2}{*}{ Variable } & \multicolumn{2}{|c|}{ Female $(N=283)$} & \multicolumn{2}{|c|}{ Male $(N=287)$} \\
\hline & Frequency & Percentage & Frequency & Percentage \\
\hline \multicolumn{5}{|l|}{ Age (years) } \\
\hline 15 & 43 & 15.2 & 45 & 15.7 \\
\hline 16 & 39 & 13.8 & 41 & 14.3 \\
\hline 17 & 45 & 15.9 & 38 & 13.2 \\
\hline 18 & 41 & 14.5 & 45 & 15.7 \\
\hline 19 & 39 & 13.8 & 52 & 18.1 \\
\hline 20 & 35 & 12.4 & 30 & 10.5 \\
\hline 21 & 41 & 14.5 & 36 & 12.5 \\
\hline \multicolumn{5}{|l|}{ Religion } \\
\hline Catholic & 184 & 65.0 & 174 & 60.6 \\
\hline Protestant & 65 & 22.9 & 58 & 20.2 \\
\hline Non-Christian & 5 & 1.8 & 8 & 2.8 \\
\hline No response & 2 & 0.8 & 3 & 1.0 \\
\hline No religion & 27 & 9.5 & 44 & 15.3 \\
\hline \multicolumn{5}{|l|}{ Hispanic/Latino-origin group } \\
\hline Mexican & 164 & 58.0 & 164 & 57.1 \\
\hline Other Hispanic/Latino & 114 & 40.3 & 110 & 38.3 \\
\hline Unknown & 5 & 1.8 & 13 & 4.5 \\
\hline \multicolumn{5}{|l|}{ Primary Language } \\
\hline English & 235 & 83.0 & 243 & 84.7 \\
\hline Spanish & 48 & 17.0 & 44 & 15.3 \\
\hline \multicolumn{5}{|l|}{ Education } \\
\hline $9^{\text {th }}$ grade or less & 46 & 16.3 & 53 & 18.5 \\
\hline $10^{\text {th }}$ grade & 42 & 14.8 & 61 & 21.3 \\
\hline $11^{\text {th }}$ grade & 65 & 23.0 & 50 & 17.4 \\
\hline $12^{\text {th }}$ grade & 58 & 20.5 & 69 & 24.0 \\
\hline 1 year college & 33 & 11.7 & 32 & 11.1 \\
\hline 2 years college & 24 & 8.5 & 14 & 4.9 \\
\hline 3 years college & 13 & 4.6 & 7 & 2.4 \\
\hline 4 years college or more & 2 & 0.8 & 1 & 0.3 \\
\hline
\end{tabular}


Table 2

Cumulative Proportion of Adolescent Remaining a Virgin at Age of 21 by Importance of Religion, Church Attendance, Traditional Attitudes on Sexuality (TAS), Gender, and Language (Acculturation)

\begin{tabular}{|c|c|c|c|}
\hline Variables & $N$ & Percentage Survival as Virgin & $\begin{array}{l}\text { Estimated Mean Age Debut } \\
(95 \% \text { Confidence Interval }[\mathrm{CI}]\end{array}$ \\
\hline \multicolumn{4}{|l|}{ Religion } \\
\hline Very important & 214 & 0.198 & $17.34(95 \% \mathrm{Cl}=16.9-17.8)$ \\
\hline Not important & 354 & 0.046 & $16.81(95 \% \mathrm{Cl}=16.5-17.1)$ \\
\hline \multicolumn{4}{|l|}{ Church attendance } \\
\hline High & 178 & 0.240 & $17.70(95 \% \mathrm{Cl}=17.2-18.2)$ \\
\hline Low & 391 & 0.056 & $16.75(95 \% \mathrm{Cl}=16.4-17.1)$ \\
\hline \multicolumn{4}{|l|}{ TAS } \\
\hline High & 175 & 0.208 & $18.01(95 \% \mathrm{Cl}=17.5-18.5)$ \\
\hline Low & 394 & 0.053 & $16.63(95 \% \mathrm{Cl}=16.3-16.9)$ \\
\hline \multicolumn{4}{|l|}{ Gender } \\
\hline Female & 283 & 0.289 & $17.29(95 \% \mathrm{Cl}=16.9-17.7)$ \\
\hline Male & 287 & 0.061 & $16.91(95 \% \mathrm{Cl}=16.5-17.3)$ \\
\hline \multicolumn{4}{|l|}{ Language } \\
\hline English & 478 & 0.080 & $16.91(95 \% \mathrm{Cl}=16.6-17.2)$ \\
\hline Spanish & 92 & 0.120 & $17.56(95 \% \mathrm{Cl}=17.0-18.1)$ \\
\hline
\end{tabular}

Edwards, Fehring, Jarrett, Haglund 15 
Table 3

Interaction Effect of Acculturation (English Language vs. Spanish Language) and Religiosity on Sexual Activity Among Latino/a Adolescents

\begin{tabular}{|c|c|c|c|c|}
\hline $\begin{array}{l}\text { Importance } \\
\text { of Religion }\end{array}$ & $\begin{array}{l}\text { Important } \\
\text { (Mean) }\end{array}$ & $\begin{array}{l}\text { Not Important } \\
\text { (Mean) }\end{array}$ & $F$ & $p$ \\
\hline \multicolumn{5}{|l|}{ Sex partners, lifetime } \\
\hline English & 1.704 & 2.446 & 5.962 & .015 \\
\hline Spanish & 1.200 & 1.422 & & \\
\hline \multicolumn{5}{|c|}{ Sex partners, past 12 months } \\
\hline English & 0.785 & 1.020 & 5.213 & .023 \\
\hline Spanish & 0.600 & 0.500 & & \\
\hline \multicolumn{5}{|l|}{ Age of sex debut } \\
\hline English & 14.911 & 14.256 & 4.890 & .027 \\
\hline Spanish & 15.689 & 15.911 & & \\
\hline Church Attendance & $\begin{array}{l}\text { Frequent } \\
\text { (Mean) }\end{array}$ & $\begin{array}{l}\text { Less } \\
\text { (Mean) }\end{array}$ & $F$ & $p$ \\
\hline \multicolumn{5}{|l|}{ Sex partners, lifetime } \\
\hline English & 1.480 & 2.509 & 6.421 & .012 \\
\hline Spanish & 0.900 & 1.541 & & \\
\hline \multicolumn{5}{|c|}{ Sex partners, past 12 months } \\
\hline English & 0.606 & 1.084 & 5.620 & .018 \\
\hline Spanish & 0.367 & 0.650 & & \\
\hline \multicolumn{5}{|l|}{ Age of sex debut } \\
\hline English & 15.595 & 13.994 & 9.202 & .003 \\
\hline Spanish & 17.033 & 15.164 & & \\
\hline $\begin{array}{l}\text { Traditional } \\
\text { Attitude Sex }\end{array}$ & $\begin{array}{l}\text { Traditional } \\
\text { (Mean) }\end{array}$ & $\begin{array}{l}\text { Permissive } \\
\text { (Mean) }\end{array}$ & $F$ & $p$ \\
\hline \multicolumn{5}{|l|}{ Sex partners, lifetime } \\
\hline English & 1.417 & 2.524 & 5.542 & 0.019 \\
\hline Spanish & 1.032 & 1.467 & & \\
\hline \multicolumn{5}{|c|}{ Sex partners, past 12 months } \\
\hline English & 0.521 & 1.118 & 6.739 & .010 \\
\hline Spanish & 0.400 & 0.633 & & \\
\hline \multicolumn{5}{|l|}{ Age of sex debut } \\
\hline English & 16.194 & 13.754 & 14.956 & .000 \\
\hline Spanish & 17.032 & 15.133 & & \\
\hline
\end{tabular}

